
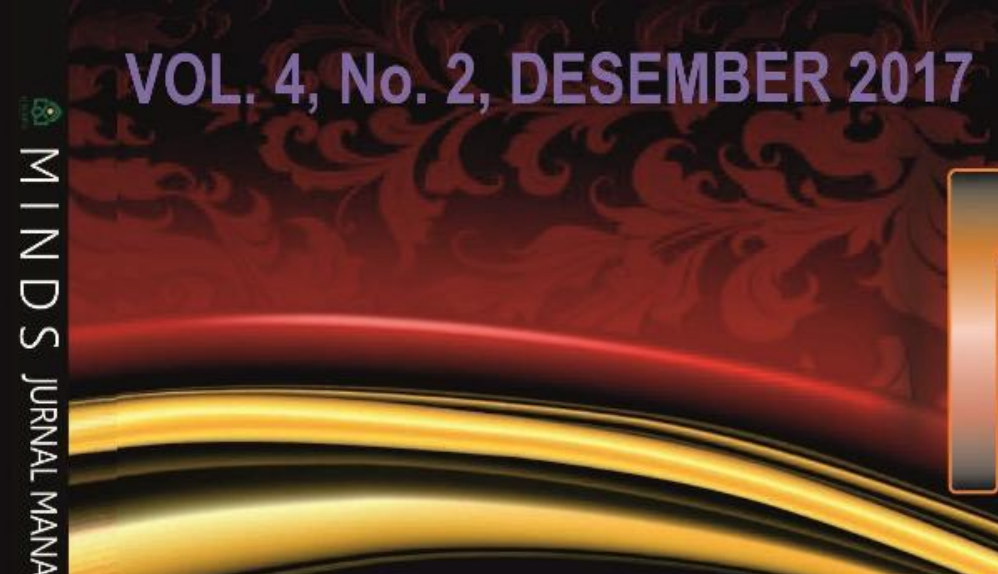

ShI

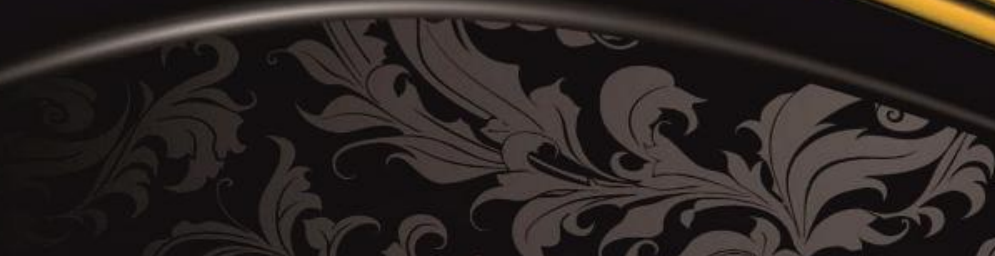

(ब)
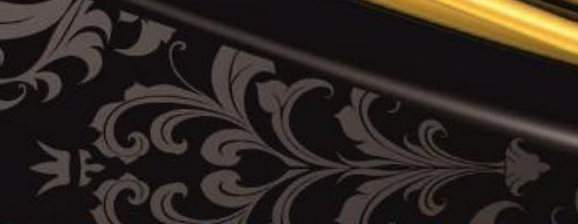

(C)

IDENTIFIKASI GAYA KEPEMIMPINAN PADA ORGANISASI RELAWAN PENANGGULANGAN BENCANA DI JAWA TIMUR

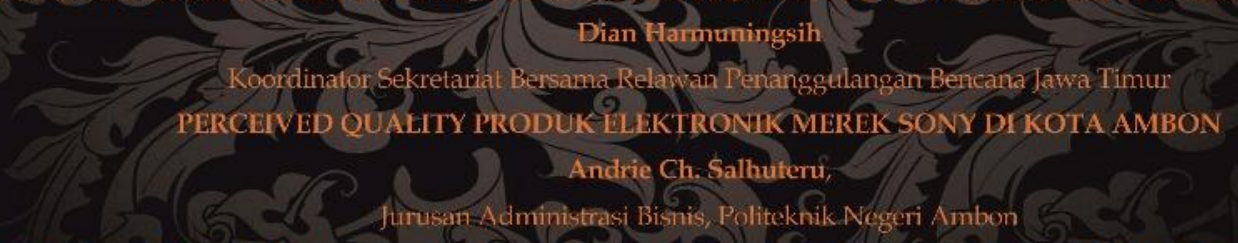

PENGARUH PROFITABILITAS, UIKUIDITAS, LEVERAGE, DAN FIRM SIZE TERHADAP KEBIJAKAN DIVIDEN PERUSAHAAN

$$
\begin{aligned}
& \text { DI INDEKS JII, PERIODE 2011-2015 } \\
& \text { Rika Dwi Ayu Parmitasari \& Hasrianto, }
\end{aligned}
$$

Jurusan Manajemen Fakultas Ekonomi dan Bisnis Islam, UIN Alauddin Makassar

FAKTOR YANG MEMENGARUHI KEPUASAN NASABAH BANK MUAMALAT CABANG AMBON

$$
\text { Gilman Pary, }
$$

Institut Agama Islam Negeri Ambon,

PENGARUH ATRIBUT PRODUK DAN PERILAKU PENCARIAN VARIASI TERHADAP PERILAKU MAHASISWA BERPINDAH MEREK PONSEL PADA FAKULTAS EKONOMI DAN BISNIS ISLAM Jusmiati \& Ahmad Efendi,

Jurusan Manajemen, Fakultas Ekonomi dan Bisnis Islam, UIN Alauddin Makassar

PENGARUH KUALITAS LAYANAN TERHADAP KEPUASAN PELANGGAN RUTE DOMESTIK GARUDA INDONESIA DI KOTA AMBON Saul Ronald Jacob Saleky,

Jurusan Administrasi Bisnis, Politeknik Negeri Ambon

PENGARUH STRES KERJA DAN IKLIM ORGANISASI TERHADAP TURNOVER KARYAWAN

$$
\text { Ludy Sapulette, }
$$

Jurusan Administrasi Bisnis, Politeknik Negeri Ambon

PENGARUH PEMBERDAYAAN DAN BUDAYA ORGANISASI TERHADAP PROFESIONALISME DOSEN

Ady Andardinata,

STIE Tri Dharma Nusantara

PENGARUH CSR, FIRM SIZE DAN INTEREST-BASED DEBT TERHADAP NILAI PERUSAHAAN PADA PERUSAHAAN MANUFAKTUR DI INDEKS JII, PERIODE 2010-2016

Wahidah Abdullah, Alim Syariati, \& Reskianti hamid

Fakultas Ekonomi dan Bisnis Islam, UNN Alauddin Makassar

ANALISIS DIMENSI KUALITAS PELAYANAN TERHADAP KEPUASAAN PASIEN PADA RSUD SYEKH YUSUF SUNGGUMINASA Asdi,

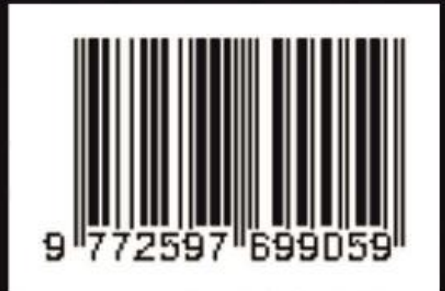

FEB, Lniversitas Muhammadiyah Makassar 
[Type text]

\section{KATA PENGANTAR}

Assalamualaikum WR. WB.

Puja dan puji syukur mari kita panjatkan ke hadirat Allah SWT, karena atas berkah dan karunia-Nya, maka Jurnal Manajemen dan Inspirasi (MINDS), Jurusan Manajemen, Fakultas Ekonomi dan Bisnis Islam, UIN Alauddin Makassar ini dapat diselesaikan. Salam dan shalawat kita haturkan kepada Nabi Muhammad SAW, sang pelita di tengah kejumudan dan kejahiliyahan, serta sumber informasi dan inspirasi yang terpercaya, al-Amiin. Terima kasih kami sampaikan kepada seluruh pihak yang terlibat dalam penyusunan jurnal Minds dari awal hingga akhir yang tidak dapat kami sebutkan satu persatu.

Adapun jurnal Minds merupakan titik kulminasi perwujudan kemampuan menulis tenaga pendidik yang berada di intra Fakultas maupun luar universitas. Tulisan akademik yang diharapkan menjadi contoh nyata jawaban dari berbagai fenomena empiris yang relevan dari sisi keilmuan Manajemen. Edisi kali ini, yaitu Vol. 4, No.2, 2017, mengupayakan adanya pengembangan dari sisi kualitas tulisan maupun sebaran wilayah penulis. Upaya ini diharapkan akan mendorong terciptanya proses yang lebih terukur baik dari penulis, mitra bestari, maupun penyunting, sehingga peningkatan kualitas publikasi ilmiah dapat diharapkan sebagai keluaran yang pasti.

Seiring dengan penerbitan jurnal ini, maka mewakili tim publikasi, saya menyampaikan rasa terima kasih yang sebesar-besarnya untuk seluruh penulis yang berpartisipasi dalam edisi kali ini, dan kepada para pembaca yang telah berkenan meluangkan waktunya untuk menelaah tulisan-tulisan yang termuat pada edisi kali ini.

Wassalamualaikum WR.WB.

Manajer Jurnal,

Dr. Alim Syariati, SE., M.Si. 


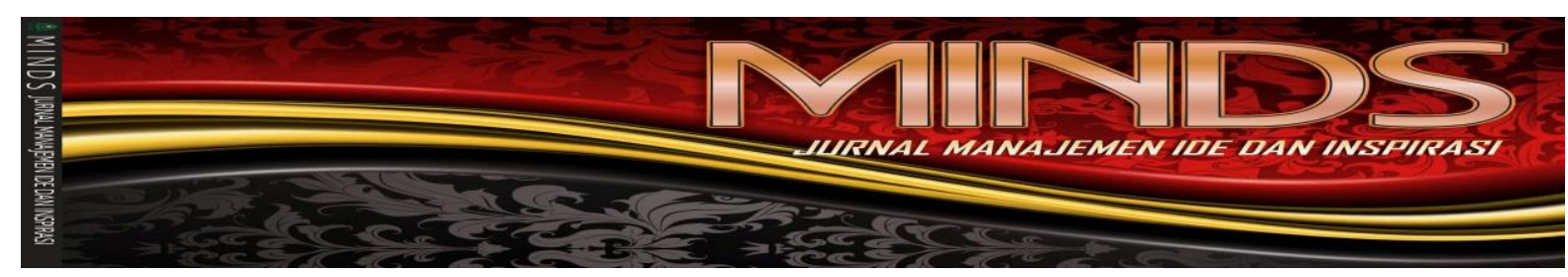

\section{DAFTAR ISI}

IDENTIFIKASI GAYA KEPEMIMPINAN PADA ORGANISASI

RELAWAN PENANGGULANGAN BENCANA DI JAWA TIMUR......

Dian Harmuningsih

Koordinator Sekretariat Bersama Relawan Penanggulangan Bencana Jawa Timur

PERCEIVED QUALITY PRODUK ELEKTRONIK MEREK SONY

DI KOTA AMBON

Andrie Ch. Salhuteru,

Jurusan Administrasi Bisnis, Politeknik Negeri Ambon

PENGARUH PROFITABILITAS, LIKUIDITAS, LEVERAGE, DAN

UKURAN PERUSAHAAN TERHADAP KEBIJAKAN DIVIDEN

SAHAM-SAHAM YANG TERDAFTAR PADA

JAKARTA ISLAMIC INDEX (JII) PERIODE TAHUN 2011-2015........

Rika Dwi Ayu Parmitasari \& Hasrianto,

Jurusan Manajemen Fakultas Ekonomi dan Bisnis Islam, UIN Alauddin Makassar

FAKTOR YANG MEMENGARUHI KEPUASAN NASABAH

BANK MUAMALAT CABANG AMBON

Gilman Pary,

Institut Agama Islam Negeri Ambon,

PENGARUH ATRIBUT PRODUK DAN PERILAKU PENCARIAN

VARIASI TERHADAP PERILAKU MAHASISWA BERPINDAH MEREK

PONSEL PADA FAKULTAS EKONOMI DAN BISNIS ISLAM............

Jusmiati \& Ahmad Efendi,

Jurusan Manajemen, Fakultas Ekonomi dan Bisnis Islam, UIN Alauddin Makassar

PENGARUH KUALITAS LAYANAN TERHADAP KEPUASAN PELANGGAN RUTE DOMESTIK GARUDA INDONESIA DI KOTA AMBON

Saul Ronald Jacob Saleky,

Jurusan Administrasi Bisnis, Politeknik Negeri Ambon

PENGARUH STRES KERJA DAN IKLIM ORGANISASI TERHADAP

TURNOVER INTENTION

Ludy Sapulette,

Jurusan Administrasi Bisnis, Politeknik Negeri Ambon

PENGARUH PEMBERDAYAAN DAN BUDAYA ORGANISASI

TERHADAP PROFESIONALISME DOSEN.

Ady Andardinata,

STIE Tri Dharma Nusantara 
PENGARUH CORPORATE SOCIAL RESPONSIBILITY (CSR), UKURAN PERUSAHAAN DAN INTEREST BASED DEBT (IBD) TERHADAP NILAI PERUSAHAAN PADA PERUSAHAAN MANUFAKTUR (YANG TERDAFTAR DI JAKARTA ISLAMIC INDEX PERIODE 2010-2016)..... Wahidah Abdullah, Alim Syariati, \& Reskianti hamid

Fakultas Ekonomi dan Bisnis Islam, UIN Alauddin Makassar

ANALISIS DIMENSI KUALITAS PELAYANAN TERHADAP KEPUASAAN PASIEN PADA RSUD SYEKH YUSUF SUNGGUMINASA

Asdi, FEB,

Universitas Muhammadiyah Makassar 


\title{
PENGARUH PEMBERDAYAAN DAN BUDAYA ORGANISASI TERHADAP PROFESIONALISME DOSEN
}

\author{
Ady Andardinata*
}

\begin{abstract}
This study aims to analyze the influence of empowerment and organizational culture on professionalism. This research is quantitative in which the research data is analyzed descriptively using Excel 2007 program and inferentially using multiple linear regression model with the help of SPSS 23 IBM program for hypothesis testing. The hypothesis in this study are: empowerment and organizational culture have a positive and significant impact on professionalism. The result of the analysis shows that empowerment and organizational culture have positive effect to professionalism. The value of the correlation coefficient $(r)$ of 0.506 means the closeness of the relationship between empowerment and organizational culture to professionalism in a moderate level. The value of determination coefficient $\left(R^{2}\right)$ of $0.256 \%$ means that empowerment and organizational culture influence $25.6 \%$ on professionalism which means there are other variables of $74.4 \%$ which can affect professionalism. The f-test shows that empowerment and organizational culture simultaneously have a significant effect on professionalism. The t-test shows that empowerment is partially significant to professionalism while the organizational culture is partially influential not significant to professionalism.

Keywords: empowerment, organizational culture, professionalism.
\end{abstract}

\begin{abstract}
ABSTRAK
Penelitian ini bertujuan untuk menganalisis pengaruh pemberdayaan dan budaya organisasi terhadap profesionalisme. Penelitian ini bersifat kuantitatif dimana data hasil penelitian dianalisis secara deskriptif menggunakan program Excell Windows 2007 dan secara inferensial menggunakan model regresi linier berganda dengan bantuan program SPSS 23 IBM untuk pengujian hipotesis. Adapun hipotesis dalam penelitian ini yaitu: pemberdayaan dan budaya organisasi berpengaruh positif dan signifikan terhadap profesionalisme. Hasil analisis menunjukkan pemberdayaan dan budaya organisasi berpengaruh positif terhadap profesionalisme. Nilai koefisien korelas (r) sebesar 0,506 artinya keeratan hubungan antara pemberdayaan dan budaya organisasi terhadap profesionalisme dalam taraf sedang. Nilai koefisien determinasi $\left(\mathrm{R}^{2}\right)$ sebesar $0,256 \%$ artinya pemberdayaan dan budaya organisasi berpengaruh $25,6 \%$ terhadap profesionalisme yang berarti masih terdapat variabel lainnya sebesar $74,4 \%$ yang dapat mempengaruhi profesionalisme. Uji-f menunjukkan bahwa pemberdayaan dan budaya organisasi secara simultan berpengaruh signifikan terhadap profesionalisme. Uji-t menunjukkan bahwa pemberdayaan secara parsial berpengaruh signifikan terhadap
\end{abstract}

\footnotetext{
*STIE Tri Dharma Nusantara, Jalan Kumala II Nomor 51 Makassar (adyandardinata10@yahoo.com)
} 
profesionalisme sedangkan budaya organisasi secara parsial berpengaruh tidak signifikan terhadap profesionalisme.

Kata kunci: Pemberdayaan, Budaya Organisasi, Profesionalisme.

\section{PENDAHULUAN}

Sumber daya manusia memegang peranan penting dalam mencapai visi dan misi suatu organisasi. Sumber daya berupa dana, teknologi, alat, metode dan lainnya yang dimiliki oleh suatu organisasi dapat berfungsi optimal jika dikelolah oleh sumber daya manusia yang profesional. Profesionalisme sudah merupakan suatu kebutuhan dan tuntutan seseorang dalam profesinya. Manajer suatu organisasi harus berusaha mendorong karyawannya agar menunjukkan profesionalisme kerja yang baik dengan cara memperhatikan potensi karyawan melalui berbagai program pemberdayaan dan penciptaan budaya organisasi yang kondusif.

Dosen merupakan kelompok pendidikan yang mngembang misi mulia dalam membentuk dan mengembangkan manajemen sumber daya manusia yang berkualitas. Hal ini seiring dengan tujuan pendidikan tinggi yaitu mempersiapkan peserta didik menjadi menjadi anggota masyarakat yang memiliki kemampuan akademik dan/atau profesional yang dapat menerapkan, mengembangkan dan/atau memperkaya khasanah ilmu pengetahuan, teknologi dan/atau kesenian (PP 60/1999). Perguruan tinggi perlu kesiapan dengan segala perangkatnya termasuk yang utama adalah dosen sebagai penggerak utama aktivitas pembejaran sehingg dosen harus mendapatkan pembinaan karier yang terencana dan proorsional apalagi tugas dan fungsi dosen semakin kompleks dikarenakan perkembangan ilmu pengatahuan yang sangat pesat dan tuntutan untuk menggunakan e-learning atau teknologi informatika tidak dapat dihindari. Keadaan ini menuntut kemampuan dosen untuk beradaptasi yang sesuai dengan kebutuhan pembangunan pendidikan tinggi sehingga kesiapan seorang dosen dalam meningkatkan kualitas dan intensitas kegiatan akademiknya mutlak menjadi kesadaran dan direncanakan secara komprehensif serta integral (Awaluddin, 2016).

Pemberdayaan dapat dilakukan berupa membuka kesempatan yang seluasluasnya pada karyawan dalam hal memperoleh akses informasi, penggunaan sumber daya yang ada, dukungan dan pengembangan diri. Pemberdayaan juga dapat berupa peningkatan kualitas karyawan melalui pendidikan dan pelatihan (diklat), penyuluhan, pembinaan dan pengawasan. Pemberdayaan bertujuan memampukan karyawan dalam melaksanakan tugas pokok dan fungsi-fungsinya. Budaya organisasi sebagai suatu pola dari asumsi-asumsi dasar yang ditemukan, diciptakan atau dikembangkan oleh suatu kelompok tertentu dengan maksud agar organisasi belajar mengatasi atau menanggulangi masalah-masalahnya yang timbul akibat adaptasi eksternal dan integrasi internal yang sudah berjalan dengan cukup baik sehingga perlu diajarkan kepada anggota-anggota baru sebagai cara yang benar untuk memahami, memikirkan dan merasakan berkenaan masalah-masalah tersebut. Budaya organisasi yang kondusif memungkinkan terciptanya profesionalisme kerja para karyawan.

Profesionalisme sebagai ciri kualitas profesional seseorang yang didukung oleh pengetahuan dan keterampilan yang relevan serta bersikap ilmiah dalam pemecahan 
masalah. Profesionalisme sudah semakin menjadi suatu kebutuhan dan tuntutan profesi dalam era modern saat ini sehingga semua pihak termasuk para dosen harus memberikan perhatian serius dalam melahirkan dan menumbuhkan kembangkan profesionalisme kerja yang tinggi dalam dirinya maupun organisasinya.

Pemberdayaan guru memiliki hubungan positif dan signifikan terhadap profesionalisme guru dan mutu pendidikan (Manaf, 2016). Ada pengaruh yang signifikan antara variabel pemberdayaan kerja terhadap profesionalisme kerja pegawai (Rudiyanto, 2016). Budaya organisasi berpengaruh kuat terhadap profesionalisme perawat pada Rumah Sakit PKU Muhammadiyah dan RSUD di Temanggung (Alfian, dkk., tahun?). Budaya organisasi berpengaruh positif dan signifikan terhadap profesionalisme dosen Universitas Riau Kepulauan (Yanti, 2013). Adapun tujuan penelitian ini berdasarkan hasil-hasil penelitian tersebut yaitu untuk menganalisis pengaruh pemberdayaan dan budaya organisasi terhadap profesionalisme dosen.

\section{TINJAUAN PUSTAKA}

\section{Pemberdayaan}

Pemberdayaan (empowerment) merupakan sebuah proses dan tujuan. Pemberdayaan sebagai proses adalah serangkaian kegiatan untuk memperkuat kekuasaan atau keberdayaan kelompok lemah dalam masyarakat. Pemberdayaan sebagai tujuan adalah meretas jalan menuju keberdayaan yang menunjuk pada keadaan atau hasil yang ingin dicapai oleh sebuah perkembangan sosial yaitu masyarakat yang berdaya, memiliki kekuasaan atau mempunyai pengetahuan dan kemampuan dalam memenuhi kebutuhan hidupnya baik bersifat fisik, ekonomi maupun sosial seperti memiliki kepercayaan diri, mampu menyampaikan aspirasi, mempunyai mata pencaharian, berpartisipasi dalam kegiatan sosial dan mandiri dalam melaksanakan tugas-tugas kehidupannya. Pengertian pemberdayaan sebagai tujuan seringkali digunakan sebagai indikator keberhasilan pemberdayaan sebagai sebuah proses. Pemberdayaan merupakan program yang mudah diucapkan tetapi sangat sulit dilaksanakan karena dibutuhkan komitmen yang kuat untuk berbagi wewenang dan tanggung jawab.

Pemberdayaan sumber daya manusia merupakan proses untuk menjadikan lebih berdaya dalam menyelesaikan masalahnya sendiri dengan cara memberikan kepercayaan dan kewenangan sehingga menumbuhkan rasa tanggung jawab. Pemberdayaan sumber daya manusia (human resources empowerment) adalah suatu kegiatan yang dilaksanakan berupa pendelegasian wewenang dan peningkatan tanggung jawab kepada sumber daya manusia untuk menjadikan lebih berdaya dalam melaksanakan tugas sesuai jabatan di dalam suatu organisasi (Rahmat, 2016:1). Pemberdayaan adalah upaya memberikan otonomi, kepercayaan atasan kepada bawahan serta mendorong mereka untuk kreatif agar dapat merampungkan tugasnya sebaik mungkin (Kadarisman, 2012:249).

Pemberdayaan sumber daya manusia disadari banyak pihak bahwa

pelaksanaannya akan memberi arti penting dan manfaat luas walaupun 
pelaksanaannya menemui banyak hambatan. Hambatan sering dijumpai dalam pelaksanaan pemberdayaan sumber daya manusia (Rahmat, 2016:14) antara lain: (1) Manajer yang mempunyai kekuasaan melakukan pemberdayaan tidak peduli masalah yang dihadapi karyawan, (2) Terdapat perasaan takut gagal karena merasa tidak pernah melakukan langkah pemberdayaan atau pernah melakukan sebelumnya namun tidak sukses sesuai harapan sehingga muncul pandangan bahwa pemberdayaan tidak akan berjalan dan tidak perlu mengubah karena keadaan sekarang baik-baik saja, (3) Keengganan karena merasa tidak punya cukup uang, staf dan peralatan untuk melaksanakan pemberdayaan atau merasa pemberdayaan bukan pekerjaannya dan bahkan beranggapan tidak mempunyai waktu untuk menjalankan serta diperparah lagi adanya perasaan bahwa serikat pekerja tidak mendukungnya dan (4) Manajer dan karyawan tidak saling mempercayai padahal syarat utama suksesnya pemberdayaan sumber daya manusia adalah adanya saling pengertian dan saling mempercayai antara atasan dan bawahan.

Manfaat pemberdayaan sumber daya manusia dalam suatu organisasi menurut Sedarmayanti dalam Kadarisman (2012: 245) yaitu: (1) Sebagai alat manajemen dalam rangka memberdayakan berbagai sumber untuk mencapai tujuan yang telah ditetapkan, (2) Sebagai pembaru manajemen dalam rangka meningkatkan kinerja, (3) Sebagai mediator terhadap pihak lain dalam meningkatkan kinerja, (4) Sebagai inisiator bagi organisasi dalam rangka memanfaatkan peluang guna meningkatkan dan mengembangkannya dan (5) Sebagai pemikir dalam rangka mengembangkan organisasi.

Adapan tahapan dalam pemberdayaan sumber daya menurut Khan dalam Kadarisman (2012: 260) sebagai berikut: (1) Keinginan (desire): Keinginan dari manajemen untuk mendelegasikan dan melibatkan karyawan, (2) Kepercayaan (trust): Membangun kepercayaan antara manajemen dengan karyawan, (3) Percaya diri (confident): Memunculkan rasa percaya diri karyawan dengan menghargai terhadap kemampuan yang dimiliki karyawan, (4) Kredibilitas (credibility): Menjaga kredibilitas dengan penghargaan dan mengembangkan lingkungan kerja yang mendorong kompetisi sehat sehingga tercipta organisasi ber-performance yang tinggi, (5) Pertanggung jawaban (accountability): Adanya pertanggungjawaban karyawan terhadap wewenang yang diberikan dan (6) Kumunikasi (communication): Adanya komunikasi yang terbuka untuk menciptakan saling memahami antara karyawan dengan manajemen yang diwujudkan dengan adanya kritik dan saran terhadap hasil dan prestasi mereka.

\section{Budaya Organisasi}

Arti budaya secara etimologis adalah pikiran, akal budi, adat istiadat sedangkan secara terminologis budaya adalah suatu hasil dari budi dan/atau daya, cipta, karya, karsa, pikiran dan adat istiadat manusia yang secara sadar maupun tidak sadar dapat diterima sebagai suatu perilaku yang beradab. Budaya (culture) organisasi adalah karakteristik kunci yang dijunjung tinggi oleh organisasi dan seluruh individu yang ada di dalamnya sebagai ciri khas pembeda dari organisasi lainnya. Kultur organisasi mengacu pada sebuah sistem makna bersama yang dianut oleh para 
anggota yang membedakan organisasi tersebut dengan organisasi lainnya (Robbins dan Judge, 2011:256). Budaya organisasi adalah nilai, norma, keyakinan, sikap dan asumsi yang merupakan bentuk bagaimana orang-orang dalam organisasi berperilaku dalam organisasi (Moeheriono, 2012:337).

Budaya organisasi secara pragmatis memiliki fungsi sangat strategis bagi kehidupan organisasi. Robbins dan Judge (2011:262) menuliskan sejumlah fungsi kultur dalam suatu organisasi sebagai berikut: (1) Berperan sebagai penentu batasbatas artinya budaya menciptakan perbedaan yang jelas antara suatu organisasi dengan organisasi lainnya, (2) Memuat rasa identitas bagi anggota organisasi, (3) Budaya untuk meningkatkan kemantapan sistem sosial, (4) Memfasilitasi lahirnya komitmen pada sesuatu yang lebih besar daripada kepentingan individu (5) Meningkatkan stabilitas sistem sosial dengan cara menyediakan standar mengenai apa yang sebaiknya dikatakan dan dilakukan oleh karyawan dan (6) Bertindak sebagai mekanisme sense making serta kendali yang menuntun dan membentuk sikap dan perilaku karyawan.

Karakteristik primer atau ciri-ciri spesifik dari budaya yang bersama-sama dan besar pengaruhnya terhadap organisasi menurut Robbins (2006: 721) yaitu: (1) Inovasi dan pengambilan risiko: Sejauhmana para karyawan didorong agar menjadi inovatif dan mengambil risiko, (2) Perhatian terhadap detail: Sejauhmana para karyawan diharapkan menunjukkan kecermatan, analisis dan perhatian terhadap detail, (3) Orientasi hasil: Sejauhmana manajemen memfokuskan pada hasil bukannya pada teknik dan proses yang digunakan untuk mencapai hasil, (4) Orientasi orang: Sejauhmana keputusan manajemen memperhatikan dampak hasil-hasil pada orangorang di dalam organisasi itu, (5) Orintasi tim: Sejauhmana kegiatan kerja diorganisasikan berdasar tim bukannya berdasar individu, (6) Keagresifan: Sejauhmana orang-orang itu agresif dan kompetitif bukannya santai-santai, dan (6) Kemandirian: Sejauhmana kegiatan organisasi menekankan dipertahankannya status quo bukannya pertumbuhan.

\section{Profesionalisme}

Profesional berarti seseorang yang memiliki keahlian khusus di dalam bidang profesinya. Profesi adalah pekerjaan yang dilandasi oleh pengetahuan tertentu. Profesionalisme dapat diartikan sebagai kualitas dan tindak-tanduk yang merupakan ciri suatu profesi dari seorang profesional. Sumber daya manusia profesional adalah mereka yang memiliki kemampuan dan penguasaan kompetensi di bidangnya masingmasing, berintegritas tinggi dan mampu melaksanakan tugas secara baik (Wello, 2014). Profesionalisme para pelaku bisnis dalam organisasi tercermin dalam bentuk naluri inovasi dan kreativitas menciptakan penyempurnaan sistem dan teknologi disertai prinsip menjunjung tinggi etika, budaya dan moral berdasarkan agama termasuk kejujuran dan keterbukaan menyangkut kepentingan publik agar organisasinya dapat tampil sebagai leader selalu terdepan. Profesionalisme dalam pemecahaan masalah berarti profesional melakukan pendekatan secara ilmiah yaitu objektif, logis, sistematik, metodik dan dapat dibuktikan (Suhartini \& Anisa, 2017). Sikap profesional 
dimaksudkan untuk menggambarkan bagaimana seseorang dalam memecahkan permasalahan pekerjaannya maka menggunakan pendekatan, perumusan masalah, mencari latar belakang teoritis dari permasalahan tersebut, meneliti faktor eksternal dan internalnya, mengajukan hipotesis pemecahan, mengembangkan metode pembuktian hipotesis dan menentukan kesimpulan pemecahan masalah secara sistematis.

Terdapat beberapa karakteristik sikap profesional yang melekat pada diri seorang profesional dalam melaksanakan profesinya (Rivai, 2009: 495) antara lain: (1) Seorang profesional dalam pemecahan masalah akan melakukan pendekatan secara ilmiah yaitu: objektif, logik, sistematik, metodik dan dapat dibuktikan, (2) Profesi dan sikap profesional dapat dipelajari karena bersifat ilmiah dan (3) Sikap profesional dimaksudkan untuk menggambarkan cara memecahkan masalah yang dihadapinya maka dia akan menggunakan pendekatan ilmiah secara sistematis dan metodis.

Seseorang dapat dikatakan profesional apabila telah memenuhi syarat-syarat (Rahmat, 2016: 32) antara lain: (1) Memiliki pengetahuan yang relevan dengan kebutuhan terkait profesinya, (2) Memiliki keterampilan yang diperlukan dalam melaksanakan pekerjaan dan (3) Bersikap ilmiah dalam pemecahan masalah yang timbul di dalam pekerjaan.

Sikap profesionalisme awal terbangunnya dari adanya sikap positivity yaitu kebanggaan dan kepercayaan diri yang dimiliki seseorang dalam menjalankan profesinya. Positivity memegang peran penting dalam mengembangkan segala potensi dan kemampuan seseorang menguasai keterampilan dan keahlian yang dibutuhkan dalam profesinya. Kepercayaan diri akan mendorong untuk mengaktualisasikan diri seseorang demi menguasai persyaratan-persyaratan kemampuan, pengetahuan, keterampilan dan sikap kerja yang dipersyaratkan untuk menjadi seorang profesional. Budaya profesionalisme yang baik dapat dibangun melalui proses edukasi yang berkesinambungan.

\section{Pengaruh Pemberdayaan terhadap Profesionalisme}

Penelitian Manaf (2016) pada Sekolah Menengah Kejuaran di Bekasi menemukan bahwa pemberdayaan guru memiliki hubungan positif dan signifikan terhadap profesionalisme guru dan mutu pendidikan. Rudiyanto, dkk (2016) dalam penelitiannya pada Fakultas Teknik Universitas Diponegoro Semarang bahwa ada pengaruh yang signifikan antara variabel pemberdayaan kerja terhadap profesionalisme kerja pegawai. Penelitian Bangun (2010) pada SMK Negeri di Kota Malang bahwa pemberdayaan mempunyai hubungan yang signifikan dengan kinerja professional guru. Hipotesis penelitian ini dirumuskan berdasarkan hasil-hasil penelitian tersebut yaitu:

H1: Pemberdayaan berpengaruh positif dan signifikan terhadap profesionalisme.

\section{Pengaruh Budaya Organisasi terhadap Profesionalisme}

Penelitian Kamilin (2013) pada SMP Al-Washliyah Kota Medan bahwa budaya organisasi secara langsung berpengaruh terhadap professional guru. Semedi (tahun?) 
dalam penelitiannya pada perusahaan konsultan yang terdaftar dalam PT. PPA Counsultants bahwa terdapat korelasi yang kuat antara budaya perusahaan dan etos kerja profesional yang menunjukkan bahwa semakin kuat budaya perusahaan maka semakin tinggi penerapan etos kerja professional. Penelitian Alfian, dkk. (tahun?) pada Rumah Sakit PKU Muhammadiyah yang dikomparasikan dengan RSUD di Temangggung bahwa terdapat hubungan yang kuat dan positif antara budaya organisasi dengan tingkat profesionalisme perawat. Hipotesis penelitian ini dirumuskan berdasarkan hasil-hasil penelitian tersebut yaitu:

$\mathrm{H} 2$ : Budaya organisasi berpengaruh positif dan signifikan terhadap profesionalisme.

\section{METODE PENELITIAN}

Waktu penelitian yang direncanakan berlangsung selama 6 bulan mulai bulan April s/d Oktober 2017 dengan mengambil lokasi penelitian di Kampus STIE Tri Dharma Nusantara dengan alamat Jalan Kumala II Nomor 51 Makassar. Peubah yang diamati dalam penelitian ini yaitu pemberdayaan dan budaya organisasi sebagai peubah independen serta profesionalisme sebagai peubah dependen. Adapun definisi operasional dan indikator masing-masing peubah yaitu: (1) Pemberdayaan adalah kegiatan untuk meningkatkan profesionalisme dosen agar lebih berdaya dalam melaksanakan profesinya dengan indikatornya: Memberikan akses memperoleh informasi, memberikan akses menggunakan sumber daya, memberikan akses dukungan, memberikan akses kesempatan untuk mengembangkan diri, memberi kesempatan mengidentifikasi permasalahan yang sedang berkembang, memberi kesempatan untuk berpartisipasi dalam pembuatan kebijakan-kebijakan, menyediakan pelatihan yang mencukupi bagi kebutuhan kerja, mendelegasikan tugas penting, menggali ide dan saran, memberikan penghargaan, mendorong persaingan kerja yang sehat, melibatkan karyawan dalam penentuan standar dan ukuran, memberikan feedback dan melaksanakan kebijakan open door communication, (2) Budaya organisasi adalah suasana atau iklim keorganisasian yang dirasakan oleh para dosen dalam melaksanakan profesinya dengan indikator: Kebebasan dalam berinovasi, dorongan agar berani mengambil risiko, kecermatan analisis dan perhatian terhadap detail, fokus pada hasil bukannya pada teknis dan proses, memperhitungkan dampak hasil-hasil pada karyawan, kegiatan kerja diorganisir berdasar tim bukannya individu, agresif dan kompetitif bukannya santai-santai, menekankan dipertahankannya status quo bukannya pertumbuhan, ketelaudanan pimpinan, tumbuhnya kreativitas kerja, privasi terjaga, adanya komunikasi yang baik, penghargaan atas prestasi dan hukuman atas pelanggaran dan (3) Profesionalisme adalah kemampuan dosen dalam melaksanakan profesinya secara baik atas penguasaan kompetensi di bidangnya, indikatornya yaitu: Penguasaan materi ajar, materi ajar sesuai satuan acara perkuliahan, kemampuan memberikan contoh aplikatif, penjelasan materi mudah dipahami, kesiapan mengajar, sistematika dalam mengajar, kemampuan memotivasi, kemampuan menarik minat belajar, kemampuan menciptakan suasana kondusif, kemampuan membimbing mahasiswa, disiplin waktu mengajar, memberi kesempatan bertanya dan diskusi saat 
mengajar, senantiasa berpenampilan menarik saat mengajar dan menanamkan kesan positif bagi mahasiswa.

Jenis data yang dipergunakan dalam penelitian ini adalah data primer yaitu data yang diperoleh melalui penelitian secara langsung terhadap objek yang diteliti. Sumber data berasal dari hasil kuisioner yang diberikan pada responden. Teknik pengumpulan data yang dilaksanakan dalam penelitian ini ditempuh dengan cara menggunakan kuisioner yang diberikan kepada para responden untuk dijawab sesuai dengan keyakinan/pendapat mereka.

Adapun kerangka konsepsi penelitian ini secara sistematika digambarkan sebagai berikut:

Gambar 1: Kerangka konsepsi penelitian

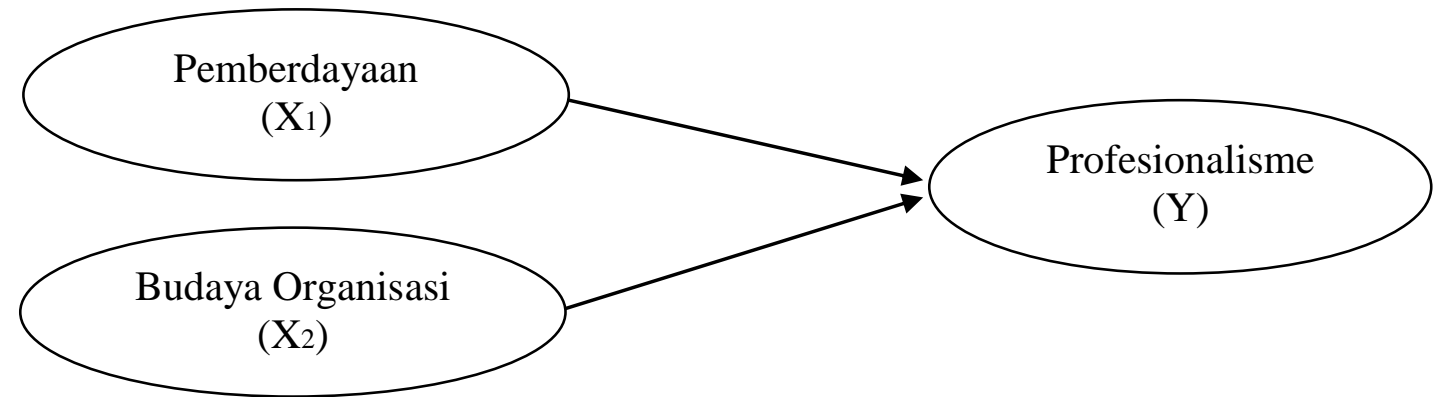

Sumber: Diolah dari berbagai sumber, 2017.

Populasi dalam penelitian ini adalah seluruh dosen yang ada di STIE Tri Dharma Nusantara Makassar yang berjumlah 75 orang. Penentuan sampel atau responden dalam penelitian ini menggunakan metode sensus yaitu seluruh populasi dijadikan sebagai responden namun hanya 50 orang yang jawabannya dapat diolah.

Metode analisis data dilakukan secara berurutan dan menginterpretasikannya sebagai berikut:

Analisis deskriptif: Analisis deskriptif untuk mendeskripsikan data karakteristik responden berupa jenis kelamin, umur, lalar belakang pendidikan dan masa kerja dalam bentuk distribusi persentase.

Uji validitas dan reliabilitas: Pengujian validitas yang umum menggunakan metode korelasi Pearson yaitu dengan cara mengkorelasikan skor item dengan skor total tanpa melakukan koreksi terhadap nilai koefisien yang overestimasi. Dasar keputusan validitas yaitu: Nilai $r$-hitung > nilai $r$-tabel dikatakan valid dan $r$-hitung $<$ nilai $r$-tabel maka tidak valid. Cara mengukur reliabilitas yang paling umum adalah menggunakan uji statistik cronbach alpha. Suatu konstruk dikatakan reliabel jika memberikan nilai cronbach alpha > 0,600 (Gazali dalam Priyatno, 2013:30) sedangkan menurut Sekaran dalam Priyatno (2013:30) bahwa pengambilan keputusan uji reliabilitas sebagai berikut:

cronbach's alpha $<0,60$ : reliabilitas buruk, cronbach's alpha 0,60 - 0,79: reliabilitas diterima, cronbach's alpha $\geq 0,80$ : reliabilitas baik.

Analisis regresi berganda: Analisis regresi linier berganda digunakan untuk mengetahui pengaruh dan arah hubungan positif atau negatif antara variabel independen dengan variabel dependen. Adapun formulasinya yaitu: 
$\hat{\mathrm{Y}}=\mathrm{c}+\mathrm{b}_{1} x_{1}+\mathrm{b}_{2} x_{2}+\mathrm{e}$

Keterangan:

$\hat{Y}$ : profesionalisme, $c$ : konstanta, $b_{1}-b_{2}$ : koefisien regresi, $\mathrm{x}_{1}$ : pemberdayaan,

$\mathrm{x}_{2}$ : budaya organisasi, $\mathrm{e}$ : error.

Analisis koefisien korelasi: Analisis koefisien korelasi (r) untuk menganalisis keeratan hubungan antara variabel independen dengan variabel dependen berkorelasi kuat atau lemah. Menurut Sugiono dalam Priyatno (2013:100) pedoman untuk menginterpretasikan hasil koefisien korelasi sebagai berikut:

0,00-0,199 : sangat rendah, 0,20 - 0,399 : rendah, 0,40-0,599 : Sedang,

$0,60-0,799$ : kuat, $0,80-1,000$ : Sangat kuat.

Analisis koefisien determinasi: Analisis koefisien determinasi $\left(\mathrm{R}^{2}\right)$ untuk menganalisis besarnya pengaruh variabel independen dan variabel lain yang tidak diukur dalam penelitian ini terhadap variabel dependen. Nilai variabel lain diperoleh dari hasil pengurangan angka satu dikurang nilai hasil perhitungan atau $100 \%$ - \% hasil perhitungan.

Uji simultan: Uji simultan (uji-f) untuk mengetahui pengaruh variabel independen secara bersama-sama terhadap variabel dependen yaitu dengan membandingkan nilai f-hitung dan f-tabel. Variabel independen dinyatakan berpengaruh secara simultan terhadap variabel dependen apabila nilai f-hitung $>$ nilai f-tabel dan nilai signifikansinya $<0,05$.

Uji parsial: Uji parsial (uji-t) digunakan untuk melihat secara parsial pengaruh dari tiap-tiap variabel independen terhadap variabel dependen yaitu dengan membandingkan nilai t-hitung dan nilai t-tabel. Variabel independen secara parsial dinyatakan berpengaruh terhadap variabel dependen apabila hasil nilai t-hitung $>$ nilai $\mathrm{t}$-tabel dan signifikansinya $<0,05$.

\section{Analisis Deskriptif Responden}

\section{PEMBAHASAN}

Analisis deskriptif responden meliputi karakteristik responden berdasarkan jenis kelamin, usia, pendidikan dan masa kerja dalam bentuk persentase (\%). Adapun deskriptif responden berdasarkan jenis kelamin sebagaimana tabel berikut ini: Tabel 1: Deskriptif responden berdasarkan jenis kelamin

\begin{tabular}{|c|c|c|c|}
\hline Nomor & Janis Kelamin & Jumlah & $\%$ \\
\hline 1 & Perempuan & 26 & 52 \\
\hline 2 & Laki-laki & 24 & 48 \\
\hline \multicolumn{2}{|c|}{ Total } & 50 & 100 \\
\hline
\end{tabular}

Sumber: Data primer setelah diolah, 2017.

Deskriptif responden berdasarkan usia sebagaimana tabel berikut ini:

Tabel 2: Deskriptif responden berdasarkan usia

\begin{tabular}{|c|c|c|c|}
\hline Nomor & Usia (tahun) & Jumlah & $\%$ \\
\hline 1 & $\leq 30$ & 4 & 8 \\
\hline 2 & $31-40$ & 25 & 50 \\
\hline
\end{tabular}




\begin{tabular}{|c|c|c|c|}
3 & $41-50$ & 15 & 30 \\
\hline 4 & $\geq 51$ & 6 & 12 \\
\hline \multicolumn{2}{|c|}{ Total } & 50 & 100 \\
\hline
\end{tabular}

Sumber: Data primer setelah diolah, 2017.

Deskriptif responden berdasarkan pendidikan sebagaimana tabel berikut ini:

Tabel 3: Deskriptif responden berdasarkan pendidikan

\begin{tabular}{|c|c|c|c|}
\hline Nomor & Pendidikan & Jumlah & $\%$ \\
\hline 1 & Tamat S-3 & 3 & 6 \\
\hline 2 & Sementara S-3 & 10 & 20 \\
\hline 3 & Tamat S-2 & 37 & 74 \\
\hline \multicolumn{2}{|c|}{ Total } & 50 & 100 \\
\hline
\end{tabular}

Sumber: Data primer setelah diolah, 2017.

Deskriptif responden berdasarkan masa kerja sebagaimana tabel berikut ini:

Tabel 4: Deskriptif responden berdasarkan masa kerja

\begin{tabular}{|c|c|c|c|}
\hline Nomor & Masa Kerja (tahun) & Jumlah & $\%$ \\
\hline 1 & $\leq 5$ & 15 & 30 \\
\hline 2 & $6-10$ & 25 & 50 \\
\hline 3 & $\geq 11$ & 10 & 20 \\
\hline \multicolumn{2}{|c|}{ Total } & 50 & 100 \\
\hline
\end{tabular}

Sumber: Data primer setelah diolah, 2017.

\section{Uji Validitas dan Reliabilitas}

Uji validitas data setiap variabel menggunakan metode Corrected Item-Total Corrected dengan bantuan program SPSS 23 IBM yang hasilnya sebagaimana tabel berikut ini:

Tabel 5: Validitas variabel pemberdayaan (X1)

Item-Total Statistics

\begin{tabular}{|c|c|c|c|c|}
\hline & $\begin{array}{c}\text { Scale Mean if } \\
\text { Item Deleted }\end{array}$ & $\begin{array}{c}\text { Scale Variance if } \\
\text { Item Deleted }\end{array}$ & $\begin{array}{c}\text { Corrected Item- } \\
\text { Total Correlation }\end{array}$ & $\begin{array}{c}\text { Cronbach's Alpha } \\
\text { if Item Deleted }\end{array}$ \\
\hline Item1 & 50.62 & 11.751 & 0.385 & 0.740 \\
Item2 & 51.04 & 12.080 & 0.406 & 0.739 \\
Item3 & 50.96 & 11.345 & 0.615 & 0.718 \\
Item4 & 51.00 & 12.490 & 0.360 & 0.744 \\
Item5 & 50.92 & 13.381 & 0.034 & 0.770 \\
Item6 & 51.04 & 12.121 & 0.321 & 0.747 \\
item7 & 50.94 & 12.425 & 0.304 & 0.748 \\
Item8 & 51.12 & 12.312 & 0.263 & 0.753 \\
item9 & 51.06 & 10.588 & 0.735 & 0.700 \\
item10 & 51.10 & 12.255 & 0.316 & 0.747 \\
Item11 & 51.04 & 11.590 & 0.507 & 0.728
\end{tabular}




\begin{tabular}{|l|l|l|l|l|} 
Item12 & 51.06 & 12.629 & 0.264 & 0.751 \\
Item13 & 51.10 & 12.296 & 0.275 & 0.752 \\
Item14 & 50.70 & 11.520 & 0.386 & 0.741 \\
\hline
\end{tabular}

Sumber: Output SPSS 23 IBM, 2017.

Diketahui nilai r-tabel pada signifikansi 0,05 dengan uji 2 sisi dan $\mathrm{df}=47$ yaitu 0,288 jika dibandingkan nilai korelasi pada tabel tersebut maka korelasi hitung > nilai r-tabel maka hampir semuanya valid kecuali pada item5, item8, item12 dan item13 yang tidak valid.

Tabel 6: Validitas variabel budaya organisasi (X2)

Item-Total Statistics

\begin{tabular}{|c|c|c|c|c|}
\hline & $\begin{array}{c}\text { Scale Mean if } \\
\text { Item Deleted }\end{array}$ & $\begin{array}{c}\text { Scale Variance if } \\
\text { Item Deleted }\end{array}$ & $\begin{array}{c}\text { Corrected Item- } \\
\text { Total Correlation }\end{array}$ & $\begin{array}{c}\text { Cronbach's Alpha } \\
\text { if Item Deleted }\end{array}$ \\
\hline Item1 & 50.86 & 9.919 & 0.311 & 0.753 \\
Item2 & 51.14 & 10.409 & 0.159 & 0.770 \\
Item3 & 51.18 & 9.824 & 0.415 & 0.742 \\
Item4 & 51.28 & 8.818 & 0.879 & 0.699 \\
Item5 & 51.30 & 10.010 & 0.372 & 0.746 \\
Item6 & 51.22 & 9.930 & 0.338 & 0.750 \\
item7 & 51.36 & 10.072 & 0.407 & 0.744 \\
Item8 & 51.24 & 10.390 & 0.353 & 0.750 \\
item9 & 51.32 & 10.059 & 0.338 & 0.750 \\
item10 & 51.22 & 9.930 & 0.338 & 0.750 \\
Item11 & 51.24 & 9.900 & 0.423 & 0.742 \\
Item12 & 51.30 & 9.439 & 0.589 & 0.726 \\
Item13 & 51.34 & 9.576 & 0.442 & 0.739 \\
Item14 & 51.08 & 10.402 & 0.117 & 0.780 \\
\hline
\end{tabular}

Sumber: Output SPSS 23 IBM, 2017.

Diketahui nilai r-tabel pada signifikansi 0,05 dengan uji 2 sisi dan $\mathrm{df}=47$ yaitu 0,288 jika dibandingkan nilai korelasi pada tabel tersebut maka korelasi hitung > nilai r-tabel maka hampir semuanya valid kecuali pada item 2 dan item 14 yang tidak valid karena nilainya $<0,288$.

Tabel 7: Validitas variabel profesionalisme $(Y)$

Item-Total Statistics

\begin{tabular}{|c|c|c|c|c|}
\hline & $\begin{array}{c}\text { Scale Mean if } \\
\text { Item Deleted }\end{array}$ & $\begin{array}{c}\text { Scale Variance if } \\
\text { Item Deleted }\end{array}$ & $\begin{array}{c}\text { Corrected Item- } \\
\text { Total Correlation }\end{array}$ & $\begin{array}{c}\text { Cronbach's Alpha } \\
\text { if Item Deleted }\end{array}$ \\
\hline Item1 & 63.68 & 16.018 & 0.869 & 0.993 \\
Item2 & 63.68 & 16.018 & 0.869 & 0.993 \\
Item3 & 63.70 & 15.520 & 1.000 & 0.992 \\
Item4 & 63.70 & 15.520 & 1.000 & 0.992 \\
Item5 & 63.72 & 15.063 & 0.932 & 0.993 \\
Item6 & 63.70 & 15.520 & 1.000 & 0.992 \\
item7 & 63.70 & 15.520 & 1.000 & 0.992 \\
Item8 & 63.70 & 15.520 & 1.000 & 0.992 \\
item9 & 63.70 & 15.520 & 1.000 & 0.992 \\
item10 & 63.70 & 15.520 & 1.000 & 0.992 \\
Item11 & 63.70 & 15.561 & 0.803 & 0.995
\end{tabular}




\begin{tabular}{|l|l|l|l|l|} 
Item12 & 63.70 & 15.520 & 1.000 & 0.992 \\
Item13 & 63.70 & 15.520 & 1.000 & 0.992 \\
Item14 & 63.72 & 15.063 & 0.932 & 0.993 \\
\hline
\end{tabular}

Sumber: Output SPSS 23 IBM, 2017.

Diketahui nilai r-tabel pada signifikansi 0,05 dengan uji 2 sisi dan $\mathrm{df}=47$ yaitu 0,288 jika dibandingkan nilai korelasi pada tabel tersebut maka korelasi hitung > nilai r-tabel maka semuanya valid.

Uji reliabitas data setiap variabel menggunakan metode Cronbach"s Alpha dengan bantuan program SPSS 23 IBM hasilnya sebagaimana tabel berikut ini:

Tabel 8: Reliabilitas variabel pemberdayaan (X1)

\section{Reliability Statistics}

\begin{tabular}{|c|c|}
\hline Cronbach's Alpha & N of Items \\
\hline 0.756 & 14 \\
\hline
\end{tabular}

Sumber: Output SPSS 23 IBM, 2017.

Tabel 9: Reliabilitas variabel budaya organisasi (X2)

\section{Reliability Statistics}

\begin{tabular}{|c|c|}
\hline Cronbach's Alpha & N of Items \\
\hline 0.760 & 14 \\
\hline
\end{tabular}

Sumber: Output SPSS 23 IBM, 2017.

Tabel 10: Reliabilitas variabel profesionalisme $(Y)$

\section{Reliability Statistics}

\begin{tabular}{|c|c|}
\hline Cronbach's Alpha & N of Items \\
\hline 0.993 & 14 \\
\hline
\end{tabular}

Sumber: Output SPSS 23 IBM, 2017.

Nilai cronbach alpha berdasarkan tabel-tabel uji realibilitas tersebut semuanya $>0,600$ maka dikatakan reliabel. Data-data yang digunakan sudah valid dan reliabel maka analisis statistik sudah dapat dilanjutkan untuk menguji hipotesis penelitian.

\section{Analisis Regresi Linier Berganda}

Analisis regresi linier berganda menggunakan bantuan program SPSS 23 IBM sebagaimana tebal berikut:

Tabel 11: Analisis regresi linier berganda

Coefficients ${ }^{a}$

\begin{tabular}{|cl|c|c|c|c|c|}
\hline \multirow{2}{*}{} & & \multicolumn{2}{|c|}{$\begin{array}{c}\text { Unstandardized } \\
\text { Coefficients }\end{array}$} & $\begin{array}{c}\text { Standardized } \\
\text { Coefficients }\end{array}$ & & \\
\cline { 2 - 5 } & Model & $\mathbf{B}$ & Std. Error & Beta & $\mathrm{t}$ & Sig. \\
\hline \multirow{2}{*}{1} & (Constant) & $\mathbf{2 . 6 1 9}$ & 0.719 & & 3.641 & 0.001 \\
& Pemberdayaan & $\mathbf{0 . 4 3 6}$ & 0.118 & 0.473 & 3.706 & 0.001 \\
& Budaya Organisasi & $\mathbf{0 . 1 4 9}$ & 0.161 & 0.118 & 0.926 & 0.359 \\
\hline
\end{tabular}

a. Dependent Variable: Profesionalisme

Sumber: Output SPSS 23 IBM, 2017. 
Persamaan regresi linier berganda berdasarkan tabel tersebut dapat dirumuskan sebagai berikut:

$$
\hat{Y}=2,619+0,436 x_{1}+0,149 x_{2}
$$

Persamaan regresi tersebut diinterpretasikan sebagai berikut: Nilai konstanta sebesar 2,619 artinya apabila variabel pemberdayaan dan budaya organisasi bernilai nol maka nilai profesionalisme tetap ada sebesar 2,619. Nilai koefisien korelasi sebesar 0,436 artinya apabila nilai pemberdayaan meningkat sebesar satu satuan maka nilai profesionalisme akan turut meningkat sebesar 0,436 satuan atau $43,6 \%$ dengan asumsi variabel independen lainnya bernilai nol atau konstan. Nilai koefisien korelasi sebesar 0,149 artinya apabila nilai budaya organisasi meningkat sebesar satu satuan maka nilai profesionalisme akan turut meningkat sebesar 0,149 satuan atau 14,9\% dengan asumsi variabel independen lainnya bernilai nol atau konstan. Persamaan regresi tersebut menunjukkan bahwa pemberdayaan dan budaya organisasi berpengaruh positif terhadap profesionalisme.

\section{Analisis Koefisien Korelasi (r)}

Analisis koefisien korelasi (r) menggunakan bantuan program SPSS 23 IBM sebagaimana tebal berikut:

Tabel 12: Analisis koefisien korelasi

\begin{tabular}{|c|c|c|c|c|}
\multicolumn{5}{|c|}{ Model Summary } \\
Model & $\mathbf{R}$ & R Square & Adjusted R Square & $\begin{array}{c}\text { Std. Error of the } \\
\text { Estimate }\end{array}$ \\
\hline 1 & $\mathbf{0 . 5 0 6}^{\mathbf{a}}$ & 0.256 & 0.224 & 0.267 \\
\hline
\end{tabular}

a. Predictors: (Constant), Budaya Organisasi , Pemberdayaan

Sumber: Output SPSS 23 IBM, 2017.

Nilai koefisien korelasi (r) sebesar 0,506 menunjukkan bahwa hubungan antara pemberdayaan dan budaya organisasi terhadap profesionalisme berkorelasi positif dalam taraf sedang (interval: 0,40 - 0,599).

Analisis Koefisien Determinasi $\left(\mathbf{R}^{2}\right)$

Analisis koefisien determinasi $\left(\mathrm{R}^{2}\right)$ menggunakan bantuan program SPSS 23 IBM sebagaimana tebal berikut:

Tabel 13: Analisis koefisien determinasi

\begin{tabular}{|c|c|c|c|c|}
\multicolumn{5}{|c|}{ Model Summary } \\
Model & $\mathrm{R}$ & R Square & Adjusted R Square & $\begin{array}{c}\text { Std. Error of the } \\
\text { Estimate }\end{array}$ \\
\hline 1 & $0.506^{\mathrm{a}}$ & $\mathbf{0 . 2 5 6}$ & 0.224 & 0.267 \\
\hline
\end{tabular}

a. Predictors: (Constant), Budaya Organisasi , Pemberdayaan

Sumber: Output SPSS 23 IBM, 2017.

Nilai koefisien determinasi $\left(R^{2}\right)$ sebesar 0,256 menunjukkan bahwa pengaruh pemberdayaan dan budaya organisasi terhadap profesionalisme sebesar 0,256 atau $25,6 \%$ yang berarti masih terdapat variabel-variabel lain sebesar $74,4 \%$ yang tidak diteliti dalam penelitian ini yang dapat mempengaruhi profesionalisme. 


\section{Uji Simultan (Uji-f)}

Uji simulttan (uji-f) menggunakan bantuan program SPSS 23 IBM sebagaimana tebal berikut:

Tabel 14: Uji-f

\begin{tabular}{|cl|c|c|c|c|c|}
\hline \multicolumn{1}{|c|}{ Model } & Sum of Squares & $\mathrm{df}$ & Mean Square & F & Sig. \\
\hline 1 & Regression & 1.152 & 2 & 0.576 & $\mathbf{8 . 0 8 5}$ & $\mathbf{. 0 0 1}^{\mathbf{b}}$ \\
& Residual & 3.348 & 47 & 0.071 & & \\
Total & 4.500 & 49 & & & \\
\hline
\end{tabular}

a. Dependent Variable: Profesionalisme

b. Predictors: (Constant), Budaya Organisasi , Pemberdayaan

Sumber: Output SPSS 23 IBM, 2017.

Hasil perhitungan uji simultan (uji-f) diperoleh nilai f-hitung sebesar 8,085 dengan nilai signifikansi simultan 0,001 dan diketahui nilai f-tabel sebesar 3,195 (pada $\mathrm{df}=47$ dan a $=0,05$ ). Hal ini menunjukkan bahwa nilai f-hitung $>$ f-tabel dan nilai signifikansi simultan $0,001<0,05$ sehingga dapat diinterpretasikan bahwa pemberdayaan dan budaya organisasi secara simultan berpengaruh signifikan terhadap profesionalisme.

Uji Parsial (Uji-t)

Uji parsial (uji-t) menggunakan bantuan program SPSP 23 IBM sebagaimana tebal berikut:

Tabel 15: Uji-t

Coefficients ${ }^{a}$

\begin{tabular}{|cl|c|c|c|c|c|}
\hline \multirow{2}{*}{} & \multicolumn{2}{|c|}{$\begin{array}{c}\text { Unstandardized } \\
\text { Coefficients }\end{array}$} & $\begin{array}{c}\text { Standardized } \\
\text { Coefficients }\end{array}$ & & \multirow{2}{*}{ Sodel } \\
\cline { 3 - 5 } & B & Std. Error & Beta & $\mathbf{t}$ & Sig. \\
\hline 1 & (Constant) & 2.619 & 0.719 & & $\mathbf{3 . 6 4 1}$ & $\mathbf{0 . 0 0 1}$ \\
& Pemberdayaan & 0.436 & 0.118 & 0.473 & $\mathbf{3 . 7 0 6}$ & $\mathbf{0 . 0 0 1}$ \\
& Budaya Organisasi & 0.149 & 0.161 & 0.118 & $\mathbf{0 . 9 2 6}$ & $\mathbf{0 . 3 5 9}$ \\
\hline
\end{tabular}

a. Dependent Variable: Profesionalisme

Sumber: Output SPSS 23 IBM, 2017.

Perhitungan uji parsial (uji-t) untuk pemberdayaan diperoleh nilai t-hitung sebesar 3,706 dengan nilai signifikansi sebesar 0,001 dan diketahui nilai t-tabel sebesar 1,678 (pada $\mathrm{df}=47$ dan $\alpha=0,05$ ). Hal ini menunjukkan bahwa nilai t-hitung $>\mathrm{t}$-tabel dan nilai signifikansi 0,001 <0,05 sehingga dapat diinterpretasikan bahwa pemberdayaan secara parsial berpengaruh signifikan terhadap profesionalisme. Adapun hasil uji parsial untuk budaya organisasi diperoleh nilai t-hitung sebesar 0,926 dengan nilai signifikansi sebesar 0,359 dan diketahui nilai t-tabel sebesar 1,678 (pada $\mathrm{df}=47 \mathrm{dan} \alpha=$ $0,05)$. Hal ini menunjukkan bahwa nilai t-hitung < t-tabel dan nilai signifikansi 0,359> 0,05 sehingga dapat diinterpretasikan bahwa budaya organisasi secara parsial berpengaruh tidak signifikan terhadap profesionalisme. 
Kesimpulan berdasarkan hasil pembahasan sebagai berikut: Pemberdayaan dan budaya organisasi berpengaruh positif terhadap profesionalisme, pemberdayaan dan budaya organisasi berkorelasi dalam taraf sedang terhadap profesionalisme, pemberdayaan dan budaya organisasi secara simultan berpengaruh signifikan terhadap profesionalisme, pemberdayaan secara parsial berpengaruh signifikan terhadap profesionalisme sehingga hipotesisis pertama $(\mathrm{H} 1)$ diterima sedangkan budaya organisasi secara parsial berpengaruh tidak signifikan terhadap profesionalisme sehingga hipotesis kedua $\left(\mathrm{H}_{2}\right)$ ditolak.

Pemberdayaan dan budaya organisasi memiliki pengaruh yang positif dan signifikan terhadap profesionalisme sehingga sepatutnya para stake holder (khususnya pemerintah dan pimpinan perguruan tingga) agar merancang, melaksanakan dan mengembangkan program-program pemberdayaan yang sesuai dengan kebutuhan serta menciptakan dan mengembangkan budaya organisasi yang kondusif demi untuk peningkatan profesionalisme dosen. Para peneliti berikutnya dapat mengembangkan variabel-variabel independen yang berpengaruh lainnya baik secara langsung maupun tidak langsung terhadap profesionalisme.

\section{DAFTAR PUSTAKA}

Alfian, N., Apriyatmoko, R. dan Sukarno. (tahun?). Komparasi Pengaruh Kekuatan Budaya Terhadap Tingkat Profesionalisme Perawat Antara Rumah Sakit PKU Muhammadiyah dengan RSUD di Temanggung. http://perpusnwu.web.id. Diakses pada tanggal 30 Januari 2016.

Awaluddin, M. 2016. Pengaruh Budaya Organisasi, Kepuasan dan Lingkungan Kerja Terhadap Kinerja Dosen UIN Alauddin Makassar. Asset. Volume 6 Nomor 1 Juni 2016: 116-125.

Bangun, D. 2010. Hubungan Pemberdayaan dan Motivasi Kerja dengan Kinerja Guru Profesional SMK Negeri di Kota Malang. Teknologi dan Kejuruan. Volume 33 Nomor 1 Februari 2010. http://journal.um.ac.id/index.php/teknologikejuruan/article/download/3088/448. Diakses pada 25 September 2017. http://journal.uin-alauddin.ac.id/index.php/assets/article/view/1605/1557. Diakses pada tanggal 25 September 2017. http://jurnal.uinbanten.ac.id/index.php/tanzhim/article/download/47/48/. Diakses pada tanggal 25 September 2017.

Kadarisman, M. 2012. Manajemen Pengembangan Sumber Daya Manusia. RajaGrafindo Persada. Jakarta.

Kamilin. 2013. Pengaruh Budaya Organisasi, Gaya Kepemimpinan Kepala Sekolah dan Motivasi Kerja terhadap Kualitas Profesionalisme Guru SMP Al-Washliyah Kota Medan. Jurnal Tabularasa PPS Unimed.

Manaf, A. 2016. Hubungan Pemberdayaan Guru terhadap Profesionalisme Guru dan Mutu Pendidikan. Tanzhim Jurnal Penelitian Manajemen Pendidikan. Volume 10 Nomor 2 Tahun 2016.

Moeheriono. 2012. Pengukuran Kinerja Berbasis Kompetensi. Edisi Revisi. Rajagrafindo Persada. Jakarta. 
Peraturan Pemerintah RI Nomor 60 Tahun 1999 Tentang Perguruan Tinggi. https://rzabdulaziz.files.wordpress.com/2013/05/pp-no-60-1999-pendidikantinggi.pdf. Diakses pada tanggal 1 Februari 2016.

Priyatno, D. 2013. Mandiri Belajar Analisis Data dengan SPSS. Mediakom. Jakarta.

Rahmat. 2016. Pemberdayaan Sumber Daya Manusia. Umitoha Ukhuwah Grafika. Makassar.

Rivai, H. V. 2009. Islamic Human Capital: Dari Teori ke Praktik Manajemen Sumber Daya Islami. PT Rajagrafindo Persada. Jakarta.

Robbins, S. P. 2006. Perilaku Organisasi. Alih bahasa oleh Molan, B. Edisi Lengkap. Index Gramedia. Jakarta.

Robbins, S. P. dan Judge, T.A. 2008. Perilaku Organisasi. Terjemahan Angelica, D., Cahyani, R. dan Rasyid, A. Penerbit Salemba Empat. Jakarta.

Rudiyanto, Paramita, P. D. dan Warso, M. M. 2016. The Influence of Development Careers and Empowerment to The Competence of Employees Through Professional Work (Study of Teaching Staff in The Neigborhood of Engineering Faculty Diponegoro University Semarang). Journal of Management. Volume 02 Nomor 02 Maret 2016. $\quad$ http://journal.um.ac.id/index.php/teknologikejuruan/article/download/3088/448. Diakses pada 25 September 2017.

Semedi, N. S. (tahun?). Pengaruh Budaya Perusahaan terhadap Etos Kerja Profesional serta Kaitannya dengan Peningkatan Kinerja Perusahaan Jasa Konsultan. http://papers.gunadarma.ac.id/files/journals/7/articles/14842/public/14842 -41702-1-PB.pdf. Diakses pada 25 September 2017.

Suhartini, Eka \& Nur Anisa. 2017. Pengaruh Kecerdasan Emosional Dan Kecerdasan Spiritual Terhadap Kinerja Perawat Rumah Sakit Daerah Labuang Baji Makassar. Jurnal Manajemen Ide dan Inspirasi, Vol. 4, No. 1, 2017

Wello, M. B. 2014. Tantangan dan Kualitas Sumber Daya Manusia di Era Globalisasi. Makalah Orasi Ilmiah. Wisuda STIE Tri Dharma Nusantara pada Tanggal 31 Desember 2014 di Grand Clarion Hotel. Makassar.

Yanti, F. 2013. Pengaruh Budaya Organisasi, Pengalaman Mengajar dan Tingkat Pendidikan Terhadap Profesionalisme Dosen Universitas Riau Kepulauan Tahun Ajaran 2012/2013. 


\title{
Penanggung Jawab \\ Ambo Asse
}

\section{Ketua/}

M. Wahyuddin Abdullah

\author{
Dewan Editor \\ Alim Syariati \\ Rusdi Prayoga \\ Andi Mulia \\ Rusnawati
}

\author{
Mitra Bestari/Reviewer \\ Ambo Asse (UIN Alauddin Makassar), \\ Firman Menne (Universitas Bosowa Makassar) \\ Suwandi Ng (Universitas Atma Jaya Makassar), \\ Agus Salim (ISEI Sul-Sel), \\ Rika Dwi Ayu Parmitasari (UIN Alauddin Makassar), \\ Ahmad Efendi (UIN Alauddin Makassar), \\ Awaluddin (UIN Alauddin Makassar), \\ Okta Nofri (UIN Alauddin Makassar), \\ Eka Suhartini (UIN Alauddin Makassar), \\ Akil Rahman (UIN Alauddin Makassar),
}

\author{
Sekretaris Penyunting \\ Rusmawandi Rara \\ Nurhikma Hawabaja \\ Roshani
}

\author{
JURNAL MINDS \\ Pusat Dokumentasi dan Publikasi IImiah \\ Jurusan Manajemen Fakultas Ekonomi dan Bisnis Islam UIN Alauddin \\ JI. Sultan Alauddin No. 33 Samata-Gowa Sul-Sel -- INDONESIA \\ Telp/HP. 081355774774, 081241840208, Fax. (0411) 8221400 \\ Website OJS: http://journal.uin-alauddin.ac.id/index.php/minds \\ Email: minds@uin-alauddin.ac.id
}




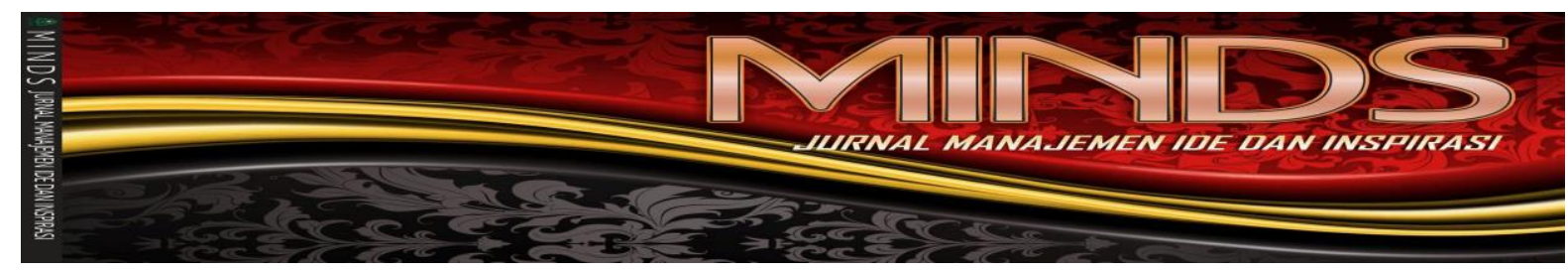

\section{KRITERIA TULISAN}

1. Panjang tulisan minimal 10 halaman dan maksimal 15 halaman

2. Menggunakan huruf Book Antiqua, font 12 , spasi 1, margin atas-bawah $3 \mathrm{~cm}$, kiri-kanan $2.54 \mathrm{~cm}$.

3. Tulisan dapat berupa hasil penelitian kuantitatif (diutamakan), penelitian kualitatitif, dan kajian teoritis dalam bidang Manajemen dengan penguatan pada integrasi keislaman.

4. Identitas penulis meliputi: nama penulis tanpa gelar, nama dan alamat afiliasi, dan alamat email penulis (contoh Alim Syariati, Fakultas Ekonomi dan Bisnis Islam UIN Alauddin, JI. HM. Yasin Limpo, NO. 63 Samata-Gowa, alim.syariati@uin-alauddin.ac.id).

5. Komposisi tulisan harus mengikuti pola berikut:

a. Judul

b. Abstrak (bahasa Indonesia dan bahasa Inggris) maksimal 150 kata dan kata kunci 3-5 kata

c. Pendahuluan (Yang didalamnya menyinggung mengenai masalah penelitian)

d. Tinjauan teoritis

e. Metode penelitian

f. Pembahasan

g. Penutup

h. Daftar pustaka

Buku: Hartono, Jogiyanto, 2004. Metodologi Penelitian Bisnis: Salah Kaprah dan pengalaman-pengalaman. Edisi 2004/2005. BPFE, Yogyakarta

Jurnal: Barney, Jay B. 1995. Looking Inside Competitive Advantage. Academy of Management, pp. 49-61

Penelitian Tidak Publikasi: Minimal sumber referensi berasal dari disertasi S3 (tapi tidak dianjurkan), dengan mengikuti format di atas

6. Menggunakan Innote

7. Waktu penting dalam penerbitan Jurnal berkala IImiah Minds, yaitu bulan Maret- Mei untuk terbitan pertama tahun berjalan, dan Oktober-November untuk terbitan kedua tahun berjalan melalui online journal system (OJS) yang bisa diakses melalui laman http://journal.uin-alauddin.ac.id/index.php/minds. Pertanyaan terkait jurnal Minds bisa disampaikan melalui email: minds@uin-alauddin.ac.id atau alim.syariati@uinalauddin.ac.id 